\title{
Prevalence and factors associated with irritable bowel syndrome among medical students of Karachi, Pakistan: A cross-sectional study
}

\author{
Syed Saad Naeem ${ }^{1}$, Efaza Umar Siddiqui ${ }^{1}$, Abdul Nafey Kazi ${ }^{3 *}$, Akhtar Amin Memon',
} Sumaiya Tauseeq Khan ${ }^{1}$ and Bilal Ahmed ${ }^{2}$

\begin{abstract}
Background: Irritable bowel syndrome (IBS) and its association with stress, has not been studied among university students in Pakistan. We investigated the prevalence and the pattern of anxiety related IBS symptoms among medical students of Karachi.

Findings: An observational case-control study was carried out at three medical colleges of Karachi, Pakistan. Random sampling was done on 360 medical students. Data was collected using validated tools "Rome III Criteria" and "Generalized Anxiety Disorder Questionnaire". Participants with IBS were diagnosed on the criteria having experienced abdominal discomfort at least 2-3 days/month associated with high level of anxiety. The apparent prevalence of IBS was found to be $28.3 \%$, with a predominance of 87 (85.29\%) females (85.29\%) over males (14.71\%). The psychological symptoms of anxiety were encountered in 57 (55.8\%) participants with IBS, among which males were $15.7 \%$ and females $84.2 \%$ respectively.
\end{abstract}

Conclusion: Students who more frequently suffer with mental stress and anxiety are more associated with IBS.

Keywords: Irritable bowel syndrome, Anxiety, Stress, Abdominal discomfort, Medical students

\section{Findings}

Irritable bowel syndrome (IBS) is a functional gastrointestinal disorder illustrated by frequent abdominal pain or discomfort associated with a change in bowel habits. IBS is one of the most common diagnoses made by medical practitioners [1]. The world wide prevalence of IBS among general population ranges from $5.7 \%$ to $34 \%$ [2]. The overall prevalence of IBS in western countries as reported by various studies ranges from $17-22 \%$. However, in Asian countries a highly variable range of prevalence has been observed i.e. $2.3-34 \%$ [3-5].

Limited data is available from Pakistan. 13\% prevalence of IBS has been found in a population based study from Abbottabad, Pakistan using Rome II criteria. IBS is a multi factorial condition and is dependent on age and sex. Symptoms appear at early adulthood but decrease as age progresses. IBS prevails mostly in persons below the age of

\footnotetext{
* Correspondence: abdulnafey@hotmail.com

${ }^{3}$ Dow University of Health Sciences, Karachi 74800, Pakistan

Full list of author information is available at the end of the article
}

25 years [6]. Literature reveals that IBS prevails more among females than males, although the reasons are not clear [5,7]. However, in an IBS study held in India, 7.9\% males and $6.9 \%$ females $[8,9]$.

Various diagnostic tools have been employed for detection of IBS including Manning criteria, Rome I criteria or Rome II criteria. Manning criteria appears to yield higher values compared to either the Rome I or II criteria [2]. Currently the Rome III criteria is being used more commonly [10].

Stress is a major contributing factor to IBS [11]. It has been postulated that stress stimulates colonic spasms [12]. Lately, many studies have reported that IBS is associated with elevated levels of emotional and psychological stress [13]. Some patients with IBS have reported anxiety disorders, depression as well as somatization disorder [2]. Psychosocial factors also affect the outcome of IBS in some patients. Mechanisms due to abnormal physical activity and visceral hypersensitivity are among other causative factors responsible for Irritable Bowel Syndrome [13].

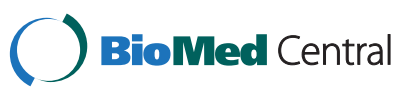

(c) 2012 Naeem et al.; licensee BioMed Central Ltd. This is an Open Access article distributed under the terms of the Creative Commons Attribution License (http://creativecommons.org/licenses/by/2.0), which permits unrestricted use, distribution, and reproduction in any medium, provided the original work is properly cited. 
It has been identified that stress is very common among medical students and is a major factor for IBS. Thus it may be possible that IBS is common among medical students. Therefore the aims of our current study were to estimate the prevalence of IBS and to estimate the association of psychological states like anxiety with IBS among medical students of Karachi, Pakistan.

It was an observational case-control study. A total of 360 medical students were included in the study which was conducted during $1^{\text {st }}-31^{\text {st }}$, September 2010. Study population comprised of first to final year students of three large medical colleges of Karachi i.e. Aga Khan University, Dow Medical College and Sindh Medical College. Convenience non-probability sampling was done to recruit the participants aged 18 and above after administration of a written informed consent.

Data was collected using two validated questionnaires: Rome III Criteria and generalized anxiety questionnaire.

\section{Rome III criteria}

The diagnosis of IBS was based on Rome III criteria. This is a clinical diagnostic criterion that outlines the symptoms and applies parameters such as frequency and duration allowing a more accurate diagnosis of IBS [10]. It defines IBS as recurrent abdominal pain or discomfort for at least 3 days/month during last 3 months associated with two or more of the following features:

1. Improvement with defecation. And/or

2. Onset associated with a change in frequency of stool. And/or

3. Onset associated with a change in form (appearance) of stool.

The diagnosis of IBS can reasonably be made by using the Rome III criteria as long as the patient does not have red flag symptoms like fever, vomiting, rectal bleeding, weight loss or other findings that might suggest other diagnoses.

The sensitivity of the Rome Criteria combined with the absence of red flag symptoms is $65 \%$, specificity is $100 \%$, the positive predictive value is $100 \%$ and the negative predictive value is $76 \%$ [14].

Severity of symptoms was obtained with a five-point scale in which 1 represented no symptoms, 2 referred to mild symptoms, 3 was for moderate symptoms, 4 represented severe symptoms and 5 reflected extremely severe symptoms that distinctly affect one's daily life.

The subjects were further classified as having constipation predominant, diarrhea predominant, mixed or unsub typed IBS.

\section{Generalized anxiety questionnaire}

A thirteen-item structured generalized anxiety questionnaire was used to determine whether or not the student had a particular anxiety related disorder. The severity of anxiety was measured by calculating the scores in the questionnaire. The result fell into four grades as follows: Scores of $<6$ determine absence of anxiety, scores within $6-8$ is low level of anxiety, $8-10$ is mild level of anxiety and $\geq 10$ determine high level of anxiety.

\section{Criterion for controls and cases}

All those participants who were found negative for IBS using Rome III Criteria were kept as control, while those who were positive for IBS were kept as cases. Further, all the cases as well as controls were screened for anxiety levels using a generalized anxiety questionnaire.

A sample size of 360 participants was calculated using a prevalence of $34 \%$ with $80 \%$ power, $0.05 \%$ significance level, $5 \%$ bond of error and adjustment for non-response rate [15].

\section{Ethics statement}

The study was approved by Ethical Review Committee of Aga Khan University Hospital.

\section{Data analysis}

Statistical analysis was done by using SPSS version 16.0. Means and standard deviations were calculated for continuous variables and proportions for categorical. Chi square test was applied to derive the p-values in order to identify the significance of the results.

\section{Demographics}

A total of 360 questionnaires were distributed, completed and analyzed with a response rate of $100 \%$. The subjects comprised of 297 (82.5\%) female and 63 (17.5\%) male students with a mean age of $20.89 \pm 2.8$ years.

\section{Prevalence of IBS}

Out of the 360 individuals screened for IBS using Rome III criteria, 102 cases were found to be positive, thus giving a prevalence of $28.3 \%$. Out of the 102 positive cases, $85.29 \%$ were females $(n=87)$ and $14.7 \%$ were $(n=15)$ males.

Age-wise distribution showed that majority of the individuals associated with IBS belonged to age-group 2123 years $(n=62,60.7 \%)$ followed by age-group $18-$ 20 years $(n=34,33.3 \%)$ (Table 1$)$.

Of the 102 individuals found positive to be IBS, about $55 \%$ were simultaneously positive for IBS type mixed. Furthermore, 25\% of the IBS-positive individuals were positive for subtype constipation (Table 2).

\section{Association with anxiety}

Thus considering the 258 individuals found negative for IBS as our control group, about 90 of them were found to be associated with anxiety using GAQ. Thus, about $34.9 \%$ controls were associated to anxiety. 
Table 1 Demographic characteristics of Medical Students

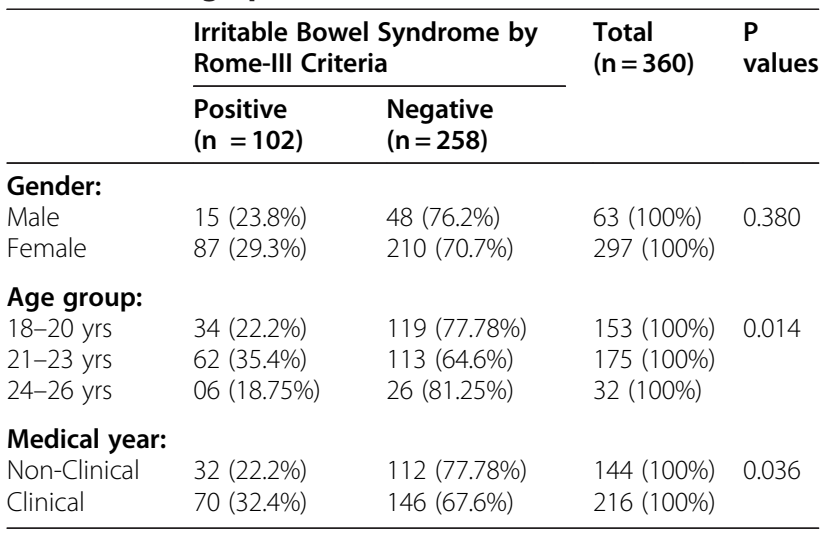

Out of our 102 cases, a total of 57 individuals were found to be positive for anxiety. Thus, about $55.8 \%$ cases were found to be associated to anxiety (Table 3).

Analyzing the association between IBS subtypes and anxiety showed that about $56 \%$ of the total individuals who were IBS subtype mixed positive, were also positive for anxiety. While only $35 \%$ people who were IBS mixed type negative were anxiety positive [Table 4]. Thus, IBS subtype mixed was found to have a significant Our study results show a prevalence of $28.5 \%$ IBS among medical students of Pakistan. Jafri et al. showed prevalence of IBS to be 34\% among college students in 2005 [11]. Despite the difference in study groups and the fact that only two studies have been carried out on IBS prevalence among university students in Pakistan, the results of both studies were similar. One of the reasons for the slight difference in the results may be the fact that medical students are generally more aware of the IBS symptoms and can manage them more efficiently than nonmedical students. Jafri et al. also found that health seeking attitude was more common among medical than non-medical students [15].

IBS prevalence in females was significantly higher than in males (5.8:1) in our study. It is steady with previous researches carried out especially on IBS among university students. Yan-Mei Tan et al. found that IBS among Malaysian medical students was diagnosed more commonly in females than males [16]. Lei Shen et al. showed that the prevalence of IBS among Chinese university students in men was $14.5 \%$ and $16.8 \%$ in women, indicating that

Table 2 Frequency of IBS sub-types in 102 positive cases

\begin{tabular}{|c|c|c|c|}
\hline \multirow[t]{2}{*}{ Types of IBS } & \multicolumn{2}{|c|}{ Frequency out of 102 IBS positive } & \multirow{2}{*}{$\begin{array}{l}\mathrm{P} \text { - } \\
\text { values }\end{array}$} \\
\hline & Positive & Negative & \\
\hline IBS Constipation & $25(24.5 \%)$ & $77(75.5 \%)$ & 0.071 \\
\hline IBS Diarrhea & $17(16.7 \%)$ & $85(83.3 \%)$ & 0.002 \\
\hline IBS Mixed & $56(54.9 \%)$ & $45(45.1 \%)$ & 0.000 \\
\hline IBS Unknown & 04 (3.9\%) & 98 (96.1\%) & 0.000 \\
\hline
\end{tabular}

Table 3 Association of Anxiety and IBS

\begin{tabular}{llll}
\hline & Cases (IBS Positive) & Controls (IBS Negative) & P-values \\
\hline Anxiety* & & & \\
Positive & $57(55.8 \%)$ & $90(34.9 \%)$ & 0.000 \\
Negative & $45(44.2 \%)$ & $168(65.1 \%)$ & \\
Total & $102(100 \%)$ & $258(100 \%)$ & \\
\hline
\end{tabular}

*as assessed by Generalized Anxiety Questionnaire.

female students had a larger prevalence. [2] The results of a very recent study in Japan on medical and nursing students also showed that women had a higher prevalence [17]. Prevalence in western countries also had a similar trend of women having a higher rate of IBS than men. On the contrary, a few reports from Mumbai [8,9], Europe and North America point out that the rate is higher in men than women. Since our study was carried out on a small scale and there is a high ratio of females to males (297:63) studying in the setup of our study population, our results had $85.29 \%(87 / 102)$ females diagnosed with IBS.

The core reason behind the difference of prevalence of IBS involving the genders is uncertain. In one of the articles they were explained by differences of socio-cultural features and health care seeking behavior between men and women or true biological differences [13]. In one of the published literature, it is reported that IBS symptoms add to the distress during menstrual cycle which leads to higher number of women experiencing the symptoms more frequently [18]. Sun Young Lee et al. concluded that gastrointestinal symptoms were more frequent in women than in men regardless of the menstrual phase. Therefore, physicians should consider a gender-based approach in clinical practice [19].

Psychosocial factors have always been widely recognized and associated with IBS. Nicholl et al. had demonstrated that anxiety, depression and sleeping disorders coexist with IBS [20]. Hazlett-Stevens also found that worry, neuroticism, anxiety sensitivity and visceral anxiety are leading factors in the occurrence of IBS [21]. Reported by Lei Shen et al., $66.2 \%$ of students met the criteria for

Table 4 Association of Anxiety with IBS sub-types

\begin{tabular}{lllll}
\hline Types of IBS & Anxiety & & Percentage & $\begin{array}{l}\text { P- } \\
\text { values }\end{array}$ \\
\cline { 2 - 3 } & Positive & Negative & & \\
\cline { 1 - 2 } $\begin{array}{l}\text { IBS Constipation } \\
\text { Positive }\end{array}$ & $25(37.3 \%)$ & $42(62.7 \%)$ & $67(100 \%)$ & 0.516 \\
$\begin{array}{l}\text { Negative } \\
\text { IBS Diarrhea }\end{array}$ & $122(41.6 \%)$ & $171(58.4 \%)$ & $293(100 \%)$ & \\
$\begin{array}{l}\text { Positive } \\
\text { Negative }\end{array}$ & $15(45.45 \%)$ & $18(54.54 \%)$ & $33(100 \%)$ & 0.571 \\
IBS Mixed & $132(40.3 \%)$ & $195(59.6 \%)$ & $327(100 \%)$ & \\
$\begin{array}{l}\text { Positive } \\
\text { Negative }\end{array}$ & $54(55.7 \%)$ & $43(44.3 \%)$ & $97(100 \%)$ & 0.001 \\
IBS Unknown & $93(35.4 \%)$ & $170(64.6 \%)$ & $263(100 \%)$ & \\
$\begin{array}{l}\text { Positive } \\
\text { Negative }\end{array}$ & $53(32.5 \%)$ & $110(67.5 \%)$ & $163(100 \%)$ & 0.003 \\
\hline
\end{tabular}


psychiatric disorder in his research conducted in 2009 [2]. Our results also established this fact with $55.8 \%$ students presenting with IBS associated with anxiety.

Medical students experience more psychological stressors due to exams and study load. Participants had a coexistence of other psychological symptoms like they easily got fatigued or had difficulty in controlling their anxiety. They had lack of concentration in different tasks. These individuals have a difficulty in controlling their anger and this interferes with their normal routine, work or university activities. The prevalence of anxiety is based on items from our structured questionnaire; a criterion is shown in the Table 5.

In our study, out of the 102 IBS positive cases, symptom subgroups analysis based on the predominant bowel habit showed that majority of these individuals had the mixed predominant subtype (54.9\%) [Table 4]. However, a similar study from Malaysia reported the predominant subtype to be only constipation [16]. It might be due to more stress levels in our study population or other factors contributing to a more severe form in our population.

There are a number of limitations to our present study. Firstly, our data is based on a selected group of medical students and does not signify the general population. Secondly, due to excessive workload on medical students, the specifications of questionnaires might not have been accurately filled. Thirdly, the extra stress on students having their exam may have exaggerated their gastrointestinal symptoms and psychological stressors affecting the results. Lastly the cause and effect relationship for the identified associated factors could not be established in detail.

The above facts clearly indicate high occurrence of IBS among medical students of Karachi which can be greatly detrimental. There is an immediate need to aware the students from the possible negative outcomes of this condition. Stress which is a major contributing factor in the development of IBS has to be tackled. Counseling sessions can play an important role in reducing the amount of stress on medical students.

Table 5 Analysis of anxiety parameters in IBS positive $(n=102)$ individuals

\begin{tabular}{lllll}
\hline Anxiety Parameters: & Females & Males & Total & Percentage \\
\hline $\begin{array}{l}\text { Easily fatigued in daily } \\
\text { routine work }\end{array}$ & 50 & 9 & 59 & $57.8 \%$ \\
$\begin{array}{l}\text { Everyday worries keep you } \\
\text { preoccupied }\end{array}$ & 48 & 8 & 56 & $54.9 \%$ \\
$\begin{array}{l}\text { Difficulty over controlling } \\
\text { anxiety and worries }\end{array}$ & 45 & 5 & 50 & $49 \%$ \\
$\begin{array}{l}\text { Trouble in keeping mind } \\
\text { on one thing }\end{array}$ & 47 & 10 & 57 & $55.9 \%$ \\
$\begin{array}{l}\text { Having headache } \\
\text { frequently }\end{array}$ & 45 & 7 & 52 & $51 \%$ \\
$\begin{array}{l}\text { Feeling restless most of } \\
\text { the time }\end{array}$ & 30 & 5 & 35 & $34.3 \%$ \\
\hline
\end{tabular}

\section{Abbreviation}

IBS: Irritable Bowel Syndrome.

\section{Competing interests}

The authors declare that they have no competing interests.

\section{Authors' contributions}

SSN: Wrote the article and synopsis for this research. EUS: Wrote the article and synopsis for this research. STK: Collected data and did data entry. ANK: Collected data and did data entry. AAM: Made edits and changes. BA: Revised and did analysis of the article. All authors read and approved the final manuscript

\section{Acknowledgements}

We would like to thank Dr. Amna Subhan consultant Gastroenterologist at Aga Khan for reviewing the manuscript. This research did not need any funds what so ever.

\section{Author details}

${ }^{1}$ Medical Students, Dow Medical College, Dow University of Health Sciences, Karachi, Pakistan. ${ }^{2}$ MSc Epidemiology and Biostatistics, Department of Medicine, Aga Khan University, Karachi, Pakistan. ${ }^{3}$ Dow University of Health Sciences, Karachi 74800, Pakistan.

Received: 6 December 2011 Accepted: 24 May 2012

Published: 24 May 2012

\section{References}

1. Sandler R: Epidemiology of irritable bowel syndrome in the United States. Gastroenterology 1990, 99(2):409.

2. Shen L, Kong H, Hou X: Prevalence of irritable bowel syndrome and its relationship with psychological stress status in Chinese university students. J Gastroenterol Hepatol 2009, 24(12):1885-1890.

3. Talley N, Zinsmeister A, Van Dyke C, Melton L: Epidemiology of colonic symptoms and the irritable bowel syndrome. Gastroenterology 1991, 101(4):927.

4. Jones R, Lydeard S: Irritable bowel syndrome in the general population. British Medical Journal 1992, 304(6819):87.

5. Heaton K, O'Donnell L, Braddon F, Mountford R, Hughes A, Cripps P: Symptoms of irritable bowel syndrome in a British urban community: consulters and nonconsulters. Gastroenterology 1992, 102(6):1962.

6. Drossman D, Sandler R, McKee D, Lovitz A: Bowel patterns among subjects not seeking health care. Use of a questionnaire to identify a population with bowel dysfunction. Gastroenterology 1982, 83(3):529.

7. Camilleri M, Choi M: Review article: irritable bowel syndrome. Aliment Pharmacol Ther 1997, 11(1):3-15.

8. Miwa H: Prevalence of irritable bowel syndrome in Japan: Internet survey using Rome III criteria. Patient Preference Adherence 2008, 2:143.

9. Thabane M, Kottachchi DT, Marshall JK: Systematic review and metaanalysis: The incidence and prognosis of post-infectious irritable bowel syndrome. Aliment Pharmacol Ther 2007, 26(4):535-544.

10. Fielding J: The irritable bowel syndrome. Part I: clinical spectrum. Clin Gastroenterol 1977, 6(3):607.

11. Jafri W, Yakoob J, Jafri N, Islam M, Ali Q: Frequency of irritable bowel syndrome in college students. J Ayub Med Coll Abbottabad 2005, 17(4):9-11.

12. Tan Y, Goh K, Muhidayah R, Ooi C, Salem O: Prevalence of irritable bowel syndrome in young adult Malaysians: a survey among medical students. J Gastroenterol Hepatol 2003, 18(12):1412-1416.

13. http://www.globalhealingcenter.com/stress-management/stress-effects.

14. Saito Y, Schoenfeld P, Locke G III: The epidemiology of irritable bowel syndrome in North America: a systematic review1. Am J Gastroenterol 2002, 97(8):1910-5.

15. Vanner S, Depew W, Paterson W, DaCosta L, Groll A, Simon J, et al: Predictive value of the Rome criteria for diagnosing the irritable bowel syndrome. Am J Gastroenterol 1999, 94(10):2912-7.

16. Shah S, Bhatia S, Mistry F: Epidemiology of dyspepsia in the general population in Mumbai. Indian J Gastroenterology 2001, 20(3):103-6.

17. Hazlett-Stevens H, Craske M, Mayer E, Chang L, Naliboff B: Prevalence of irritable bowel syndrome among university students:The roles of worry, neuroticism, anxiety sensitivity and visceral anxiety. J Psychosomatic Res 2003, 55(6):501-5. 
18. Triadafilopoulos $G$, Finlayson $M$, Grellet $C$ : Bowel dysfunction in postmenopausal women. Women \& health. 1998, 27(4):55-66.

19. Okami Y, Kato T, Nin G, Harada K, Aoi W, Wada S, Higashi A, Okuyama Y, Takakuwa S, Ichikawa H, Kanazawa M, Fukudo S: Lifestyle and psychological factors related to irritable bowel syndrome in nursing and medical school students. J Gastroenterol 2011, 46(12):1403-1410.

20. Sun-Young Lee, Jeong Hwan Kim, In-Kyung Sung, Hyung-Seok Park, ChoonJo Jin, Won Hyeok Choe, So Young Kwon, Chang Hong Lee, Kyoo Wan Choi: Irritable Bowel Syndrome Is More Common in Women Regardless of the Menstrual Phase: A Rome II-based Survey. J Korean Med Sci 2007, 22(5):851-854

21. Nicholl B, Halder S, Macfarlane G, Thompson D, O'brien S, Musleh M:

Psychosocial risk markers for new onset irritable bowel syndrome-Results of a large prospective population-based study. Pain 2008, 137(1):147.

doi:10.1186/1756-0500-5-255

Cite this article as: Naeem et al.: Prevalence and factors associated with irritable bowel syndrome among medical students of Karachi, Pakistan: A cross-sectional study. BMC Research Notes 2012 5:255.

\section{Submit your next manuscript to BioMed Central and take full advantage of:}

- Convenient online submission

- Thorough peer review

- No space constraints or color figure charges

- Immediate publication on acceptance

- Inclusion in PubMed, CAS, Scopus and Google Scholar

- Research which is freely available for redistribution 